\title{
The statistics of a clinical case
}

\author{
"It is easy to lie with statistics. It is hard to tell the truth without it."
}

Andrejs Dunkels

Some interesting discussions have been observed, in social networking, what is preached as an excessive appreciation of researchers for statistical analysis, in lieu of clinical experience. As a clinician and researcher with some learning in statistics, I believe it is a mistake to separate the two issues.

Recently, a 14 year-old patient who came to me for orthodontic retreatment, presented in the routine radiographic records a radiolucent image with clear borders and approximately $1 \mathrm{~cm}$ in diameter. Immediately I asked for a pathologist evaluation, who, facing an imminent suspect of idiopathic bone cavity, or traumatic bone cyst, recommended a biopsy. The histological examination confirmed the diagnostic hypothesis. It was indeed a cyst. Her mother said that the remote probability of a neoplasia brought concern to friends and family. She had heard a similar story from a friend whose teenage daughter also would have used braces. The mother's logic had caused the following inference:

“- So, Doctor... I think the use of these appliances is causing these injuries. Look, two teenagers and these images were detected in both."

I explained to the mother that, despite the logical observation, we cannot prove this cause-effect relationship imagined, only with the data reported. That's because she should take into consideration that it is normal for all patients who wear braces to take X-rays often and therefore it is more likely to detect such findings in subjects who underwent orthodontic treatment - simply because they take more $\mathrm{X}$-rays. The X-ray, in turn, facilitates the discovery of a bone injury, a fact already reported. ${ }^{1}$ Orthodontic treatment seems to be, moreover, a confounding factor and at least for now, science is lacking in well designed studies on this relationship.
The situation described above illustrates how the human mind is set to find the order, even where there is none. Our mind was built to identify a definite cause for every event, and find it hard to accept the influence of unrelated or random factors. This false logic can lead us to take wrong decisions. Unfortunately, this is the pattern of observations when we consider only our own clinical experience to decide therapy. The fatality of error will be greater the lower our sample is (i.e., clinical experience). Our brain, by several factors, does not have the ability to eliminate the confounding factors associated with a phenomenon. For this reason we appeal to the aid of statistics. But we cannot deceive ourselves, it also does not represent the end of the road and, often reaffirms the thought of Dunkels, in the title.

The hypothesis to be tested should examine, through a well-designed study, the incidence of bone cysts in a group of individuals who received orthodontic treatment, and compare them with a control group without orthodontic intervention. After the data collecting, the results would require a statistical approach to define what is the probability of the observed difference between groups not having occurred by chance - or, in other words, that the association between the incidence of cysts and orthodontic treatment is actually true. In statistics, the probability of a fortuity (or the difference to be a lie) is measured by the $p$ value, present in almost all scientific studies. Therefore, the smaller the $\mathrm{p}$ value is, the smaller the chance of error in stating the association.

Of course, the experience accumulated over the years of clinical activity should not be thrown away. In fact, it is estimated that only $15 \%$ of our clinical decisions are supported by scientific evidence. 
Therefore, most of the attitudes are taken based on the clinical routine, or what we have been transmitted by our tutors. Science itself, which is settled into solid methods, has been in some battles on the decision about what is more appropriate for a given clinical situation. If we consider solely the opinions held by clinical experience, it increases our probability of error, the same p value. In other words: our truth being, in fact, a lie.

As an orthodontist, with some clinical experience, and a researcher, with some learning in statistics, I believe that the best evidence is not a single study, even a randomized clinical trial, the highest level of evidence from primary studies. Depending on the fact, I consider that, despite its importance, the clinical experience alone is not the best guideline for better treatment in an individual case. Thus, it is not A or B, but the sum $\mathrm{A}+\mathrm{B}$. The union of scientific knowledge, derived from the best available evidence - and therefore, with appropriate statistics - and the consolidated clinical experience produces the greatest chances of success when treating a particular patient.

Thus, for younger people, while clinical experience walks slowly, you better hurry up and keep up to date. Enjoy the wealth of scientific research and eminent masters using this modus operandi. For the more experienced clinicians, scientific reading permits a reassessment of its regression or clinical procedures performed on a daily basis, and the identification of the infamous confounders. After all, as the French philosopher Diderot stated: "He who examined himself is truly advanced in the knowledge of others." So you have to learn to question your own beliefs. Spend time searching evidences that prove you are wrong, also search for reasons that show how much you're right. This approach will give you a lower chance of error when treating your next patient. However, consider that this is only the thought of a perpetual learner, who at this time already started doubting his own convictions.

Have a nice reading!

David Normando - Editor-in-chief davidnor@amazon.com.br
REFERENCES

1. Guerra ENS, Damante JH, Janson GRP. Relação entre o tratamento ortodôntico e o diagnóstico do cisto ósseo traumático. R Dental Press Ortod Ortop Facial. 2003 mar-abr;8(2):41-8. 